\title{
The Research on Mandarin Chinese Consonants from Perspective of EPG
}

\author{
Hongzhi $\mathrm{Yu}$ \\ Key Lab of China's National Linguistic Information Technology, Northwest University for Nationalities \\ KLCNLIT,NUN \\ Lanzhou, China \\ e-mail : yuhongzhi@hotmail.com
}

\author{
Yanhua Duan \\ Key Lab of China's National Linguistic Information \\ Technology, Northwest University for Nationalities \\ KLCNLIT,NUN \\ Lanzhou, China \\ e-mail : 446549989@qq.com
}

\author{
Dongxu Zhang \\ Key Lab of China's National Linguistic Information \\ Technology, Northwest University for Nationalities \\ KLCNLIT,NUN \\ Lanzhou, China \\ e-mail :dolleehom@163.com
}

\begin{abstract}
This paper aims at analyzing the contact between tongue and hard palate during production of Mandarin Chinese consonants by means of Electropalatograph (EPG). Their tongue characteristics of onset are obtained: plosives have tongue-palate contact mainly in anterior, and completely block involve more contact during production; under the same manner of place, affricates involve more contact than fricatives; laterals concentrate their tonguepalate contacts on alveolar and anteriority, resulting high anteriority and centrality; nasal involve alveolar contact with high anteriority and centrality but low posteriority. Using EPG to record the contact state of pronunciation can help recording and describing voice more objectively and more precisely, enriching and modifying some interpretation and theory.
\end{abstract}

Keywords- Electropalatography; Mandarin Chinese; Articulation Places and Manners

\section{INTRODUCTION}

Traditional linguistics on the basis of consonants of auditory perception, conducted static description for its articulation places and manners, but ignored the dynamic process of pronunciation. The research of EPG makes up for the shortage of the static research of consonants from traditional linguistics perspective, so acc ording to the research of EPG we can check an d make up for the research results of consonants. Up to now, the research of EPG as follows: Ellis used EPG confirmed the continuous speech phenomenon about velar consonant and alveolar consonant in English pronunciation; Engwall have combined with MRI, EMA and EPG to reconstructed three-dimensional model of tongue motion about Switzerland voice; our sc hool teacher Da Wa applied for National Natural Science Foundation of China $<<$ The research on Tibetan pronunciation physical model from perspective of EPG $>>$. In order to reveal the complexity of the tongue palatal contact state, and make the research of
Mandarin Chinese more scientific and accurate, this article selects ten Single consonants after vowels /a / in Mandarin Chinese, and draws each parameters by related software, then analysis to provide one new method for languages of ethnic minority areas.

\section{EXPERIMENTAL PROGRAM}

\section{A. Brief introduction of EPG}

Artificial plate is a kind of device in EPG (Electropalatography), which is a kind of technique to access the contact between tongue and hard palate during production [1]. Artificial plate fit tightly on the teeth and parts of the hard palate of the oral cavity jaw, determine tongue palate contact in the state of pronunciation. This article uses Electronic false palatine of 62 electrodes designed by Reading University, electrodes divide eightin-line, in addition to the first row has six electrodes, the rest have eight electrodes are arranged symmetrical, the first row in upper incisors palatal lateral margin, the eight row on the border between the soft and hard palate, the former four rows have one half area of the latter four rows. [2]In process of pronunciation, velar needs raise your tongue and drop your soft palate, in order not to effect the person's pronunciation, electronic false palatine doesn't cover the soft palate area. [3]So, EPG can't col lect velar completely. EPG collects data at the rate o f $100 \mathrm{hz}$ per second, and can describe the immediate change of speech by $5 \mathrm{~ms}$ per frame of time acquisition interval. The following picture is a false palatine of 62 electrodes and the number of electrodes in every part. 


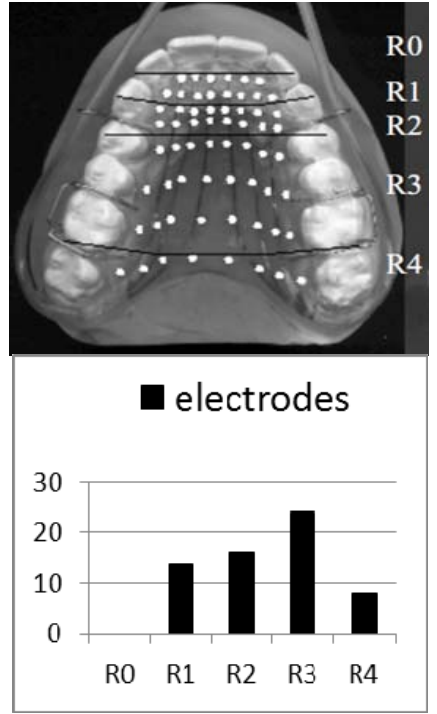

Figure 1. The False Palatine OWNS the Number of EleCtrode IN EACH PARTITION

\section{B. Parameters settings}

If we want to design parameters for electronic false palatine, we must classify function of false palatine. The following draw is the functional partition of false palatine, the left divides electronic false palatine into $t$ hree partitions: gum, soft and hard palate, the right divides into two partitions: anterior palate and post-palatal.

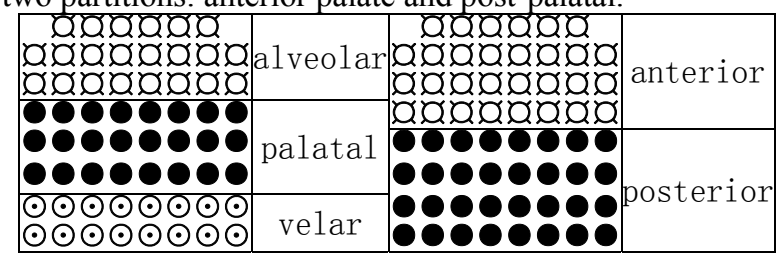

Figure 2. The Functional Partition of False Palatine

1 ) Contact proportion in function area of artificial plate

TC $($ Total Contact $)=$ contact electrodes $(n) /$ the to tal number of electrodes;

AC (Alveolar Contact $)=$ contact electrodes of alveolar(n)/ the total number of electrodes;

PC ( Palatal Contact) $=$ contact electrodes of palatal(n)/ the total number of electrodes;

VC $($ Velar Contact) = contact electrodes of velar(n)/ the total number of electrodes;

Ant ( Anterior Contact) = contact electrodes of anterior(n)/ the total number of electrodes;

Pos ( Posterior Contact ) = contact el ectrodes of posterior(n)/ the total number of electrodes;

2) Contact electrode distribution index.There are three contact electrode distribution indexes: Contact
Anteriority() ( CA), Contact Posteriority ( CP ) 、 Contact Centrality (CC).

$\mathrm{CA}=(\log (1 *(\mathrm{R}(8) / 8)+9 *(\mathrm{R}(7) / 8)+81 *(\mathrm{R}(6) / 8)+729 *(\mathrm{R}(5) /$ $8)+6567 *(\mathrm{R}(4) / 8)+59049 *(\mathrm{R}(3) / 8)+531441 *(\mathrm{R}(2) / 8)+358$ $7227 *(\mathrm{R}(1) / 6)+1)) /(\log (4185105)) .[4]$.

$\mathrm{CP}=(\log (1 *(\mathrm{R}(1) / 6)+1)+9 *(\mathrm{R}(2) / 8)+81 *(\mathrm{R}(3) / 8)+729 *(\mathrm{R}$ $(4) / 8)+6567 *(\mathrm{R}(5) / 8)+59049 *(\mathrm{R}(6) / 8)+531441 *(\mathrm{R}(7) / 8)+$ $3587227 *(\mathrm{R}(8) / 8)) /(\log (4185105)) \cdot[5]$.

$\mathrm{CC}=(\log (1 *((\mathrm{C}(1)+\mathrm{C}(8)) / 14)+17 *((\mathrm{C}(2)+\mathrm{C}(7)) / 16)+289 *$ $((\mathrm{C}(3)+\mathrm{C}(6)) / 16)+4913 *((\mathrm{C}(4)+\mathrm{C}(5)) / 16)+1)) /(\log (5220+$ 1)).[6].

There are only thirteen signal consonants spell with vowel $/ \mathrm{a} /$, but $/ \mathrm{k} / 、 / \mathrm{kh} / 、 / \mathrm{h} /$ have latter place o $\mathrm{f}$ articulation are beyond the scope of EPG collection, and doesn' $t$ in research. The rest ten $\mathrm{c}$ onsonants form blockage or obstruction by tongue-palate, so this article researches the rest.

\section{Contact Proportion IN Function AREA of ARtificial Plate}

EPG can real-time record tongue-palate contact in langue, this article researches the biggest one that is target frame of consonants followed by vowel/a/. The following chart is the biggest tongue-palate contact followed by vowel/a/. This article analyses mandarin Chinese consonants from the above parameters of EPG. In order to observe, all parameters are amplified $100 \%$ on the basis of the original values, the unit is $\%$.

TABLE I. THE BIGGEST TONGUE-PALATE CONTACT OF TEN MANDARIN CHINESE CONSONANTS

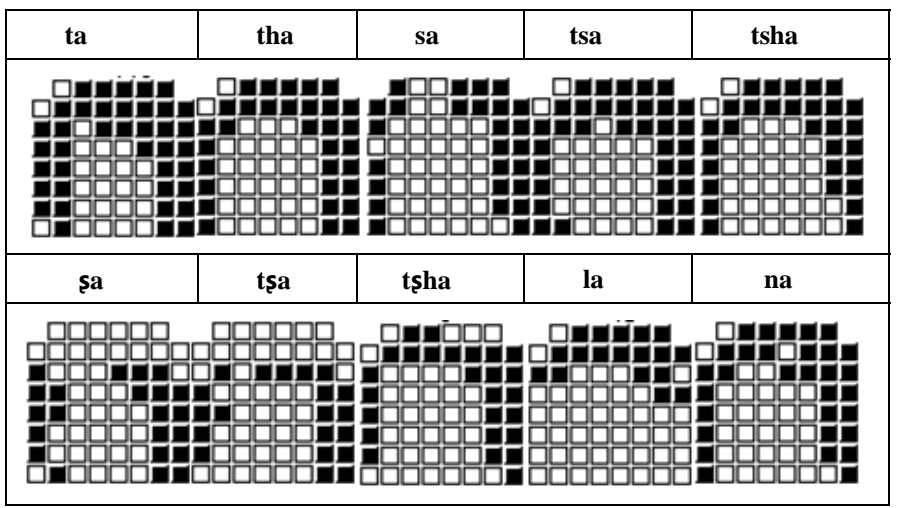

A Total Contact(TC)

Total Contact (TC) comes tongue-palate contacts electrodes of the biggest one divide he t otal number of electrodes, it reflects tongue and hard palate condition of every sound. The following picture is the total contact of ten of Mandarin Chinese consonants. 


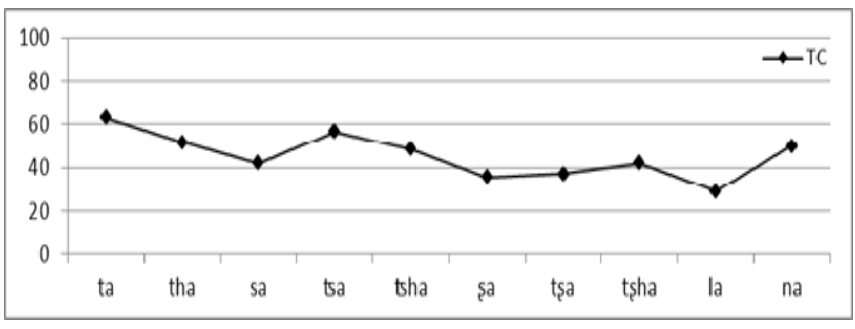

Figure 3. THE TOTAL CONTACT OF TEN MANDARIN CHINESE CONSONANTS FOLLOWED BY VOWEL/A/

TC is total contact, from this picture we can know, the value TC of plosive $/ \mathrm{t} / \mathrm{T} / \mathrm{th} / \mathrm{isn}$ ' $\mathrm{t}$ very big, that is because the tip of the tongue against the gum during production, place of articulation is mainly in alveolar during production of $/ \mathrm{t} / \mathrm{V} / \mathrm{th} /$. Fricatives/s/, $/ \mathrm{s} /$ do not completely block, so their TC is smaller than the same position of affricates/ts/、/tsh/、/ts/ / $/ \mathrm{tsh} /$. The tip of the tongue form blockage and airflow outflows from margin of the tongue during production of laterals. Nasals do not have much tongue-palate contacts, that is because the tip of the tongue form blockage during production

\section{$B$ contact area of each partition when there are three functional zone}

We divide artificial plate to three functional zone for alveolar、palatal、velar, then it can reflect topography in every zone of Mandarin Chinese consonants clearly. This article selects ten Mandarin Chinese consonants which followed by vowel/a/ draws and analyses their parameters AC、PC、 VC as follows:

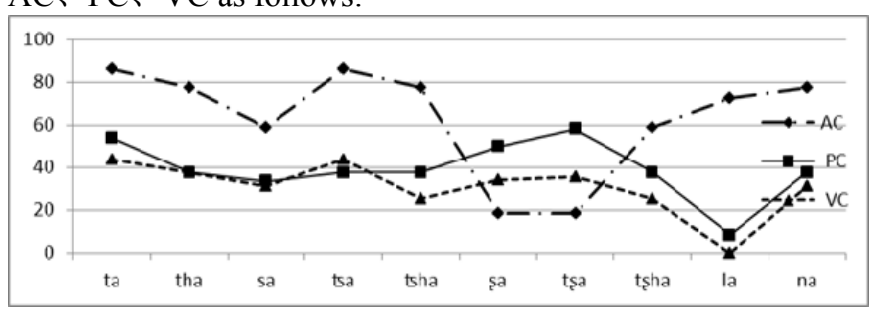

Figure 4. AC、PC AND VC OF TEN MANDARIN ChINESE CONSONANTS FOLLOWED BY VOWEL/A/

The parameters AC、 PC and VC and separately alveolar、palatal、velar contact, from this picture we can know, the value of plosive is that AC is large and PC、VC is small that is because the tip of the tongue against the gum during production, place of articulation is mainly in alveolar during production of $/ \mathrm{t} / \mathrm{V} / \mathrm{th} /$. Fricatives $/ \mathrm{s} / \mathrm{V} / \mathrm{s} /$ do not completely block, so their TC is smaller than the same position of affricates/ts/、/tsh/、/tss/、/tssh/,that is to say fricatives have more tongue-palate contacts th an affricates. Supradental/ts/、/tsh/、/s/ have former place of articulation and tongue-palate contacts mainly in anteriority, $\mathrm{AC}$ is higher than $\mathrm{PC} 、 \mathrm{VC}$ of the three sounds; blade-palatal $/ \mathrm{ts} / 、 / \mathrm{tsh} /$ 、/s/have higher $\mathrm{PC}$ th an $\mathrm{AC}$ 、 $\mathrm{VC}$, and their place of articulation mainly in palatal. The tip of the tongue form blockage during production of laterals, so AC is very big, $\mathrm{PC} 、 \mathrm{VC}$ are very small. Nasals have higher $\mathrm{AC}$ than $\mathrm{PC} 、 \mathrm{VC}$, the tip of the tongue against the alveolar during articulation.

\section{Contact area of each partition when there are two functional zone}

We divide artificial plate to two functional zone for anteriority, posteriority, then it can r eflect topography in every zone of Mandarin Chinese consonants clearly. The following is parameters Ant 、 Pos of ten Mandarin Chinese consonants followed by vowel/a/.

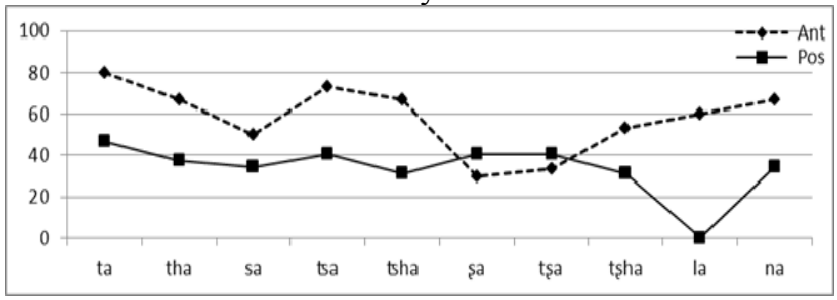

Figure 5. ANT 、 POS OF TEN MANDARIN ChINESE CONSONANTS FOLLOWED BY VOWEL/A

The parameters Ant and Pos are separately anterior and posterior, from this picture we can kn ow that the value of plosive is : Ant is large and Pso is small, that is because the tip of the tong ue against the gum during production, place of articulation is mainly in anterior place during production of $/ \mathrm{t} / 、 / \mathrm{th} /$. Fricatives $/ \mathrm{s} / 、 / \mathrm{s} /$ do not completely block, so their TC is smaller than the same position of affricates/ts/ $/ \mathrm{tsh} / 、 / \mathrm{ts} / 、 / \mathrm{tsh} /$, that is to say fricatives have more tongue-palate contacts than affricates. The mainly place of articulation is in anterior, so the Ant is higher than Pos of Supradental/ts/ 、/tsh/ 、/s/; bladepalatal $/ \mathrm{ts}_{\mathrm{s}} /$ / $/ \mathrm{s} \mathrm{s} / \mathrm{V} / \mathrm{s} / \mathrm{have}$ similar Ant and Pos, and their place of articulation mainly in palatal. The tip of the tongue form blockage during production of laterals, so Ant is very big, Pos ar e very small. Nasals have higher Ant than Pos, the tip of the tongue against the alveolar during articulation, the blockage in alveolar place.

\section{CONTACT Electode Distribution INDEX}

Contact Anteriority ( CA ) 、 Contact Posteriority (CP) and Contact Centrality (CC) are separately the anteriority v posteriority and centrality, values $r$ ange between 0 to 1 , and the numerical value is more close to 1 , more anterior, posterior and cen tral. The following is parameters CA、CP and CC of ten Mandarin Chinese consonants followed by vowel/a/. 


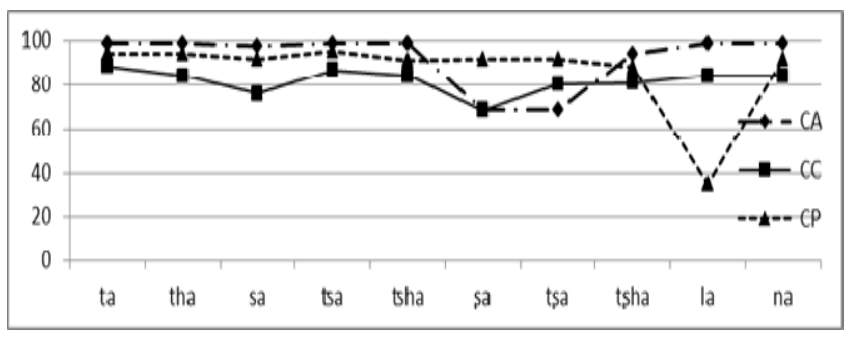

Figure 6. CA、CP AND CC OF TEN MANDARIN ChINESE Consonants FOLLOWED BY VOWEL/A/

$\mathrm{CA} 、 \mathrm{CP}$ and $\mathrm{CC}$ are s eparately anteriority 、 posteriority and centrality, from this picture we can know, $\mathrm{CA} 、 \mathrm{CP}$ and $\mathrm{CC}$ of plosive are very big, indicating the anteriority v posteriority and centrality of $\mathrm{t} / \mathrm{v} / \mathrm{th} /$ are strong. Fricatives $/ \mathrm{s} / \mathrm{s} / \mathrm{s}$ do not completely block, so their $\mathrm{TC}$ is smaller than the sa me position of affricates/ts/ $/ \mathrm{tsh} / 、 / \mathrm{ts} / 、 / \mathrm{tsh} /$,that is to say fricatives have more tongue-palate contacts than affricates. The tip of the tongue form blockage during production of laterals, so CA and $\mathrm{CC}$ are very big, $\mathrm{CP}$ is very small. Nasals have $\mathrm{h}$ igh $\mathrm{CA} 、 \mathrm{CP}$ and $\mathrm{CC}$, the tip of the tongue against the alveolar during articulation., indicating the anteriority, posteriority and centrality of $t /$ / th/ are strong, there are many tonguepalate contacts in anterior and posterior.

\section{SUMMARY}

According to the above analysis, put the conclusions presented as the form of tables as the following table.

TABLE II. EACH PARAMETERS OF TEN MANDARIN CHINESE CONSONANTS FOLLOWED BY VOWEL/A/

\begin{tabular}{|c|c|c|c|c|c|c|c|c|c|}
\hline & TC & AC & PC & VC & Ant & Pos & CA & CP & CC \\
\hline plosives & + & ++ & +- & +- & + & +- & ++ & ++ & ++ \\
\hline Fricatives- & - & - & - & - & - & - & - & - & - \\
\hline
\end{tabular}

\begin{tabular}{|c|c|c|c|c|c|c|c|c|c|}
\hline affricates & & & & & & & & & \\
\hline laterals & - & + & - & 0 & +- & 0 & ++ & - & ++ \\
\hline nasal & +- & + & - & - & + & - & ++ & ++ & ++ \\
\hline
\end{tabular}

plosives have tongue-palate contact mainly in anterior, and completely block i nvolve more contact during production; under the sa me manner of place, and affricates involve more contact than fricatives; laterals concentrate their tongue-palate contacts on alveolar and anteriority, resulting high anteriority and centrality; nasal involve alveolar contact with high anteriority and centrality but low posteriority.

\section{ACKNOWLEDGMENT}

This research was financially supported by the Innovation of scientific research project of Northwest University for Nationalities (Grant NO. ycx13152), the Major Key Projects of Social Science Foundation of China (Grant NO.10\&ZD125), National Natural Science Foundation of China (Grant NO.61262052) and the major projects of the Education Institute (Grant NO.210263).

\section{REFERENCES}

[1] MorganBarry RA, EPG from square one: An overview of electropalatography as an aid to therapy, Clinic L inguistics and Phonetics, vol.3, pp. 81-91, 1989.

[2] Hardcstle WJ, Jones W and Knight C, New developments inelectropalatography: a state-of-the-art report, Clin Lingui Phonet, vol. 3, pp. 1-38, 1989.

[3] Zhen Yuling,hasi and Baiyin mend. The EPG database of mongolian speech,J. collected papers of Mongolia,vol.3,2004.

[4] Farnetani, E.(1997). Coarticulation and connected speech processes. In Hardcastle, W. J.\& Laver, J. (eds.) The Handbook of Phonetc Sciences, 371-404. Oxford: Blackwell pub-lisher.

[5] Li Jian. The research on the ar ticulatory process of consonants in Mandarin by using EPG. Zhejian Univeristy, 2004.

[6] Li Jian. The research on the ar ticulatory process of consonants in Mandarin by using EPG. Zhejian Univeristy, 2004. 